\title{
WILLOW BEETLE — EGG TO PUPA
}

by RALPH UNDERWOOD

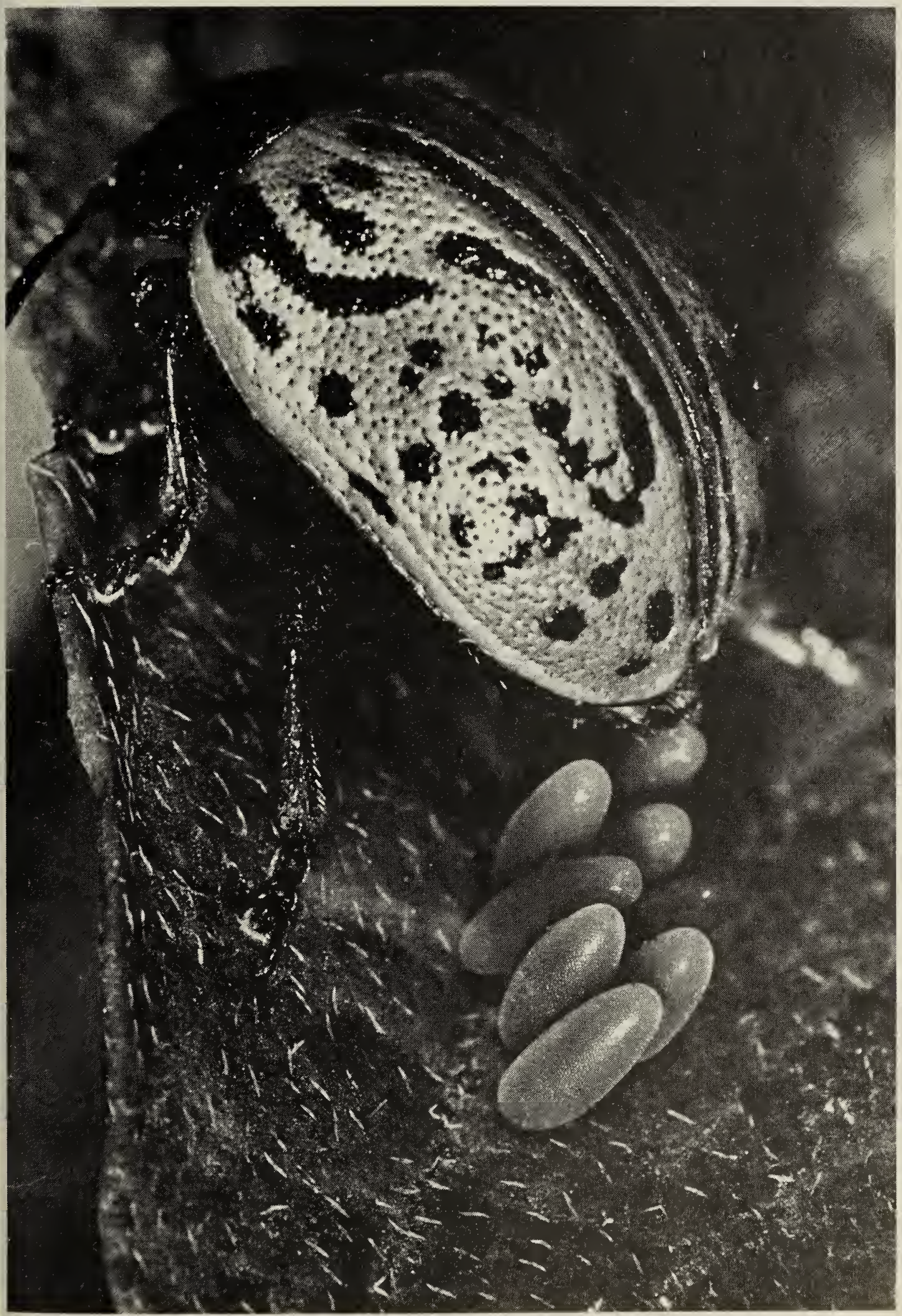

Laying eggs on leaf $\quad$ x 16 


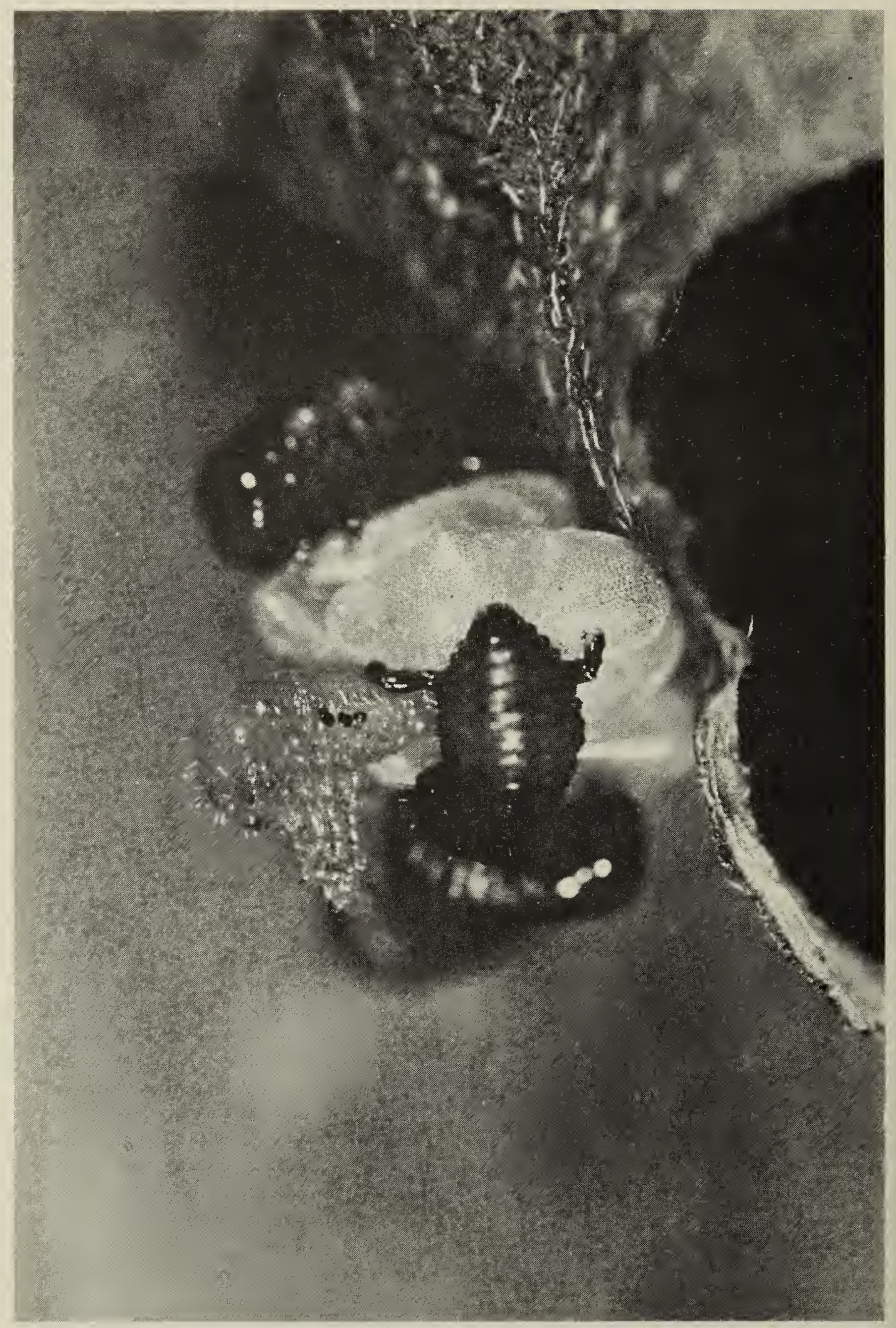




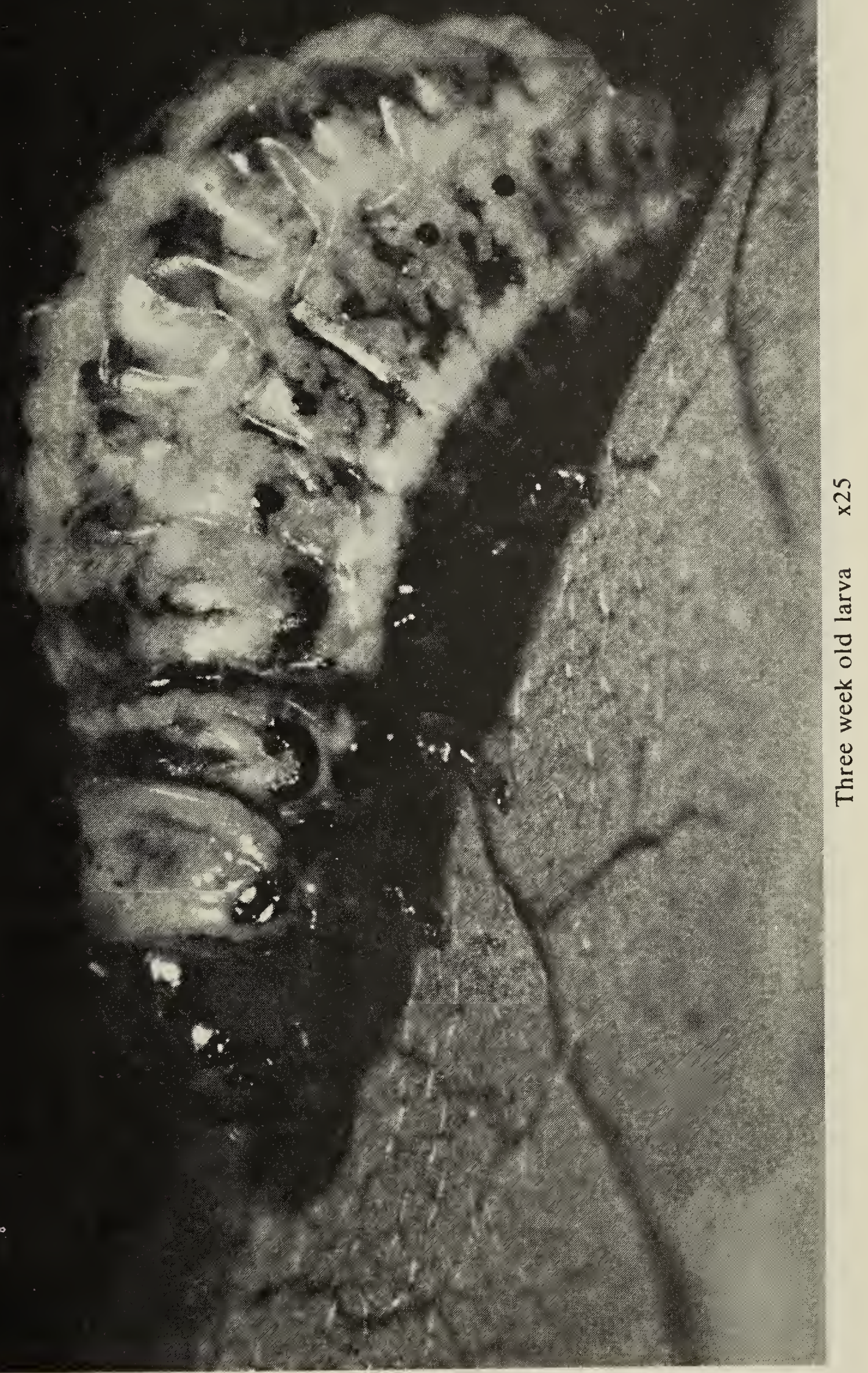

September, 1975. 33(3) 


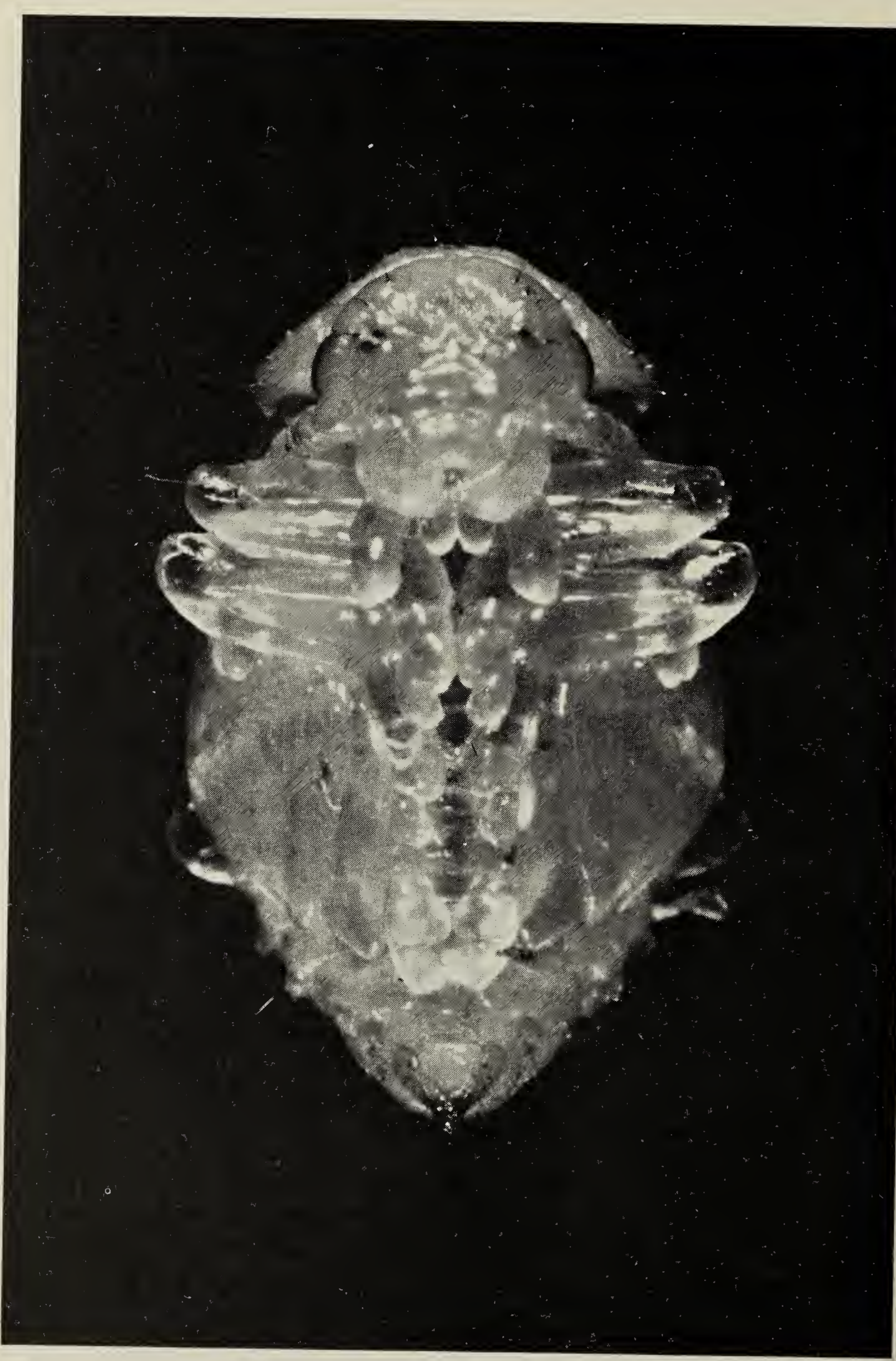

